doi.org/ 10.51891/rease.v7iro.2657

\title{
OS BENEFÍCIOS MEDICINAIS DA PRÓPOLIS VERDE (BACCHARIS DRACUNCULIFOLIA DC), UTILIZADA POPULARMENTE ATRAVÉS DE SUAS PROPRIEDADES ANTIINFLAMATÓRIA E ANTIBACTERIANA
}

\author{
Rosilene Oliveira da Silva Paranhos ${ }^{1}$ \\ Luciana Santos de Oliveira ${ }^{2}$
}

RESUMO: A própolis verde (Baccharis dracunculifolia DC) é uma substância de cor e consistência variada coletada por abelhas da espécie Apis mellifera em inúmeras plantas, retiradas dos brotos. Sua composição química também tem a capacidade de ser variada, mas que consegue unir acima de 200 substancias diferentes extraídas da própria própolis, e com qualidades terapêuticas. A que se destaca como uma das melhores substâncias, retirada dos brotos, chama-se flavonoides e a dos ácidos fenólicos, pois é atribuída a elas grande parte das atividades biológicas constatadas para a própolis. Os flavonoides e os terpenoides, Baccharis dracunculifolia é oriundo do cerrado brasileiro e considerada a principal fonte botânica da própolis verde. A própolis tem despertado o interesse cientificamente nos últimos anos, devido a inúmeras propriedades biológicas, tais como antimicrobiana, antitumoral, imunomoduladora, entre outras, bem como por seu potencial para o desenvolvimento de tratamento terapêutico.

Palavras-chave: Tratamento Terapêutico. Própolis. Própolis Verde.

ABSTRAT: The green própolis (Baccharis dracunculifolia DC) is a substance of varying color and consistency collected by bees of the species Apis mellifera in numerous plants, taken from the shoots. Its chemical composition also has the ability to be varied, but it can unite above 200 different substances extracted from propolis itself, and with therapeutic qualities. What stands out as one of the best substances, removed from the shoots, is called flavonoids and phenolic acids, because they are attributed much of the biological activities found for propolis. Flavonoids and terpenoids, Baccharis dracunculifolia originates from the Brazilian cerrado and considered the main botanical source of green propolis. Propolis has aroused scientific interest in recent years, due to numerous biological properties, such as antimicrobial, antitumor, immunomodulatory, among others, as well as its potential for the development of therapeutic treatment.

Keywords: Therapeutic Treatment. Propolis. Propolis Green

\footnotetext{
${ }^{\mathrm{I}}$ Paranhos Formação acadêmica: Curso de Farmácia Instituição: UNIG

${ }^{2}$ Universidade Iguaçu. E-mail: flordejava2@yahoo.com.br
} 


\section{INTRODUÇÃO}

A própolis verde (Baccharis dracunculifolia DC), é oriunda da colheita das abelhas espécie Apis melífera, uma resina produzida através da mistura de resinas de árvores, cera, pólen, alguns vegetais e a secreção extraída das próprias abelhas (LUTOSA,2008).

Com a mistura de produtos vegetais, a sua composição química pode variar de acordo com a inserção de vegetais extraídos pelas abelhas, que nem sempre se utiliza os mesmos componentes, contendo diversos compostos de natureza fenólica, além de óleos voláteis, ácidos aromáticos, ceras, resinas, bálsamo, pólen, além de elementos essenciais como magnésio, níquel, cálcio, ferro e zinco. (RIBEIRO; COLOMBARI, 2006)

Devido a esse riquíssimo poder, a própolis verde se tornou em algo de utilização popular na sociedade, pois tem a capacidade de produzir atividades farmacológicas de cunho terapêutico e sem restrição de uso, tais como antimicrobiana, antioxidante, antiinflamatória, imunomoduladora, hipotensiva, cicatrizante, anestésica, anticâncer, anti-HIV e anticarcinogênica. (RIBEIRO; COLOMBARI, 2006).

A própolis verde é um produto extraído da espécie vegetal Baccharis dracunculifolia DC, conhecida popularmente como alecrim-do-campo, espécie responsável pela coloração esverdeada, a própolis possui capacidade em produzir uma substância química na presença dos flavonoides, os quais desempenham atividade antiinflamatória, antioxidante e antibacteriana. Considerada um componente riquíssimo em promover tratamento terapêutico devido as suas características farmacológicas no trato de diversas afecções (LUSTOSA et al., 2008).

A própolis de alecrim-do-campo ou própolis verde, constitui um produto tipicamente brasileiro e, devido ao fato de ser altamente eficaz no combate a uma série de microrganismos, é altamente valorizada no mercado internacional, sendo que, somente no Japão, movimenta um mercado da ordem de setecentos milhões de dólares ao ano (NASCIMENTO et al., 2008).

A própolis verde é conhecida por essa nomenclatura devido a sua hegemonia que é um material resinoso de consistência viscosa desenvolvido pela ação das 
abelhas que coletam a matéria-prima oriunda de variedades de plantas como brotos, cascas e exsudatos de árvores, transformando-as dentro da colmeia pela adição de secreções salivares e cera, um produto natural com a eficácia qualitativa de uso terapêutico (BURDOCK, 1998; ADELMANN, 2005).

O uso de produtos medicinais naturais tem aumentado cada vez mais, direcionando um interesse populacional voltado ao uso de produtos apícolas tais como mel, geleia real, pólen, própolis, dentre outros. A utilização da própolis verde tem sido uma das melhores alternativas terapêuticas como atividade antimicrobiana, anti-inflamatória, cicatrizante, anestésica e anticarciogênica, quanto pela possibilidade de aplicação na indústria farmacêutica e alimentícia (ADELMANN, 2005).

A própolis verde durante esses últimos 30 anos, tornou-se uma ferramenta para intensos estudos farmacológicos e químicos, devido a suas propriedades terapêuticas que produz, incluindo atividade antifúngica, antiviral, antibacteriana, antioxidante (LEMOS,2013).

Por ser um produto natural, e que dependendo da sua utilização, consegue produzir resultados qualitativos de grande proporção. De acordo com SANTOS (2018), foi identificado através de testes fitoquímicos a atividade antioxidante de extratos etanólicos da própolis da Argentina, Austrália, China, Hungria e Nova Zelândia, correlacionando com o conteúdo total de polifenóis e flavonoides encontrados nas própolis onde as própolis com forte atividade antioxidante continham compostos antioxidativos como o kaempferol e o éster fenílico do ácido caféico (CAMPOS,2019).

O uso da suplementação de extrato de própolis verde como terapêutica, apresenta uma melhora significativa do quadro geral do paciente e da qualidade de vida. Devido às propriedades anti-inflamatórias, antioxidantes e alto poder imunológico, a própolis pode auxiliar na estabilização da progressão em doenças simples e de alta complexidade devido as suas propriedades terapêuticas (ADELMANN, 2005).

A produção de própolis tem se tornado produto de grande valor para muitas famílias brasileiras, que tem buscado neste nicho de mercado o aumento da produção apícola como fonte de renda familiar. A própolis verde, assim como a própolis 
vermelha, atualmente são produtos que agregam alto valores para o mercado brasileiro, e de grande interesse no mercado internacional, principalmente no mercado japonês (HOJO, 2017).

\section{OBJETIVOS}

Objetivo Geral

Apresentar a importância da cultura popular e suas tradições resgatando o conhecimento milenar da utilização da Própolis e da Própolis Verde, e suas devidas utilizações medicinais como anti-inflamatória e antibacteriana.

\section{Objetivos Específicos}

- Abordar o histórico do conhecimento popular e suas tradições milenares na utilização da própolis;

- Descrever as características química e farmacológica da própolis verde;

- Identificar as propriedades terapêuticas antiinflamatória e bacteriana da própolis verde.

\section{METODOLOGIA}

Este estudo foi desenvolvido em revisões bibliográficas, através de consulta em revistas, artigos científicos nacionais e internacionais indexados, dissertações, monografias, teses, bases de dados eletrônicas da U.S. Nattional Libray of Medicine and The National Institutes of Health (PubMed), Biblioteca Virtual em Saúde (EDENF,LILACS, MEDLINE), Scientific Electronic Library Online (SciELO) e Google Acadêmico.

\section{JUSTIFICATIVA}

A busca de produtos naturais de cunho medicinais tem feito com que o mercado brasileiro desenvolva um crescimento progressivo voltado aos produtos apícolas nos últimos anos, devido a procura por produtos naturais que atendam anseios específicos do consumidor em relação à sua ação terapêutica e que tivesse a mesma eficácia de fármacos que produzem atividade antifúngica, antiviral, antibacteriana, antioxidante e antiinflamatória, fez com que o Brasil, a indústria farmacêutica e a produção de produtos naturais investisse em tecnologia, pesquisa e desenvolvimento de novos produtos (LEMOS,2013). 
A produção de própolis tem se tornado produto de grande valor para muitas famílias brasileiras, que tem buscado neste nicho de mercado o aumento da produção apícola como fonte de renda familiar. A própolis verde, assim como a própolis vermelha, atualmente são produtos que agregam alto valores para o mercado brasileiro, e de grande interesse no mercado internacional, principalmente no mercado japonês (ADELMANN, 2005).

\section{DESENVOLVIMENTO}

\section{I CONTEXTO HISTÓRICO}

Desde o surgimento da civilização, o homem desenvolveu meios para utilizar produtos naturais como terapia medicinal para suprir suas demandas relacionados a problemas de saúde. Tendo a capacidade de desenvolver várias formas de medicamentos extraídos de plantas brutas (Alecrim do campo), (Figura I) além das tradicionais preparações Galênicas (ex.: extratos). Considerando a dos mais importantes descobertos, foi as propriedades do uso da própolis verde, como um produto natural extraído das abelhas e que produz efeitos significativos como terapia, passando a ser utilizados durante séculos pela humanidade. Seu emprego já era descrito pelos assírios, gregos, romanos, incas e egípcios. No antigo Egito (i7oo a.C. "cera negra") era utilizada como um dos materiais para embalsamar os mortos (ADELMAN,2005).

FIGURA r: Alecrim do campo

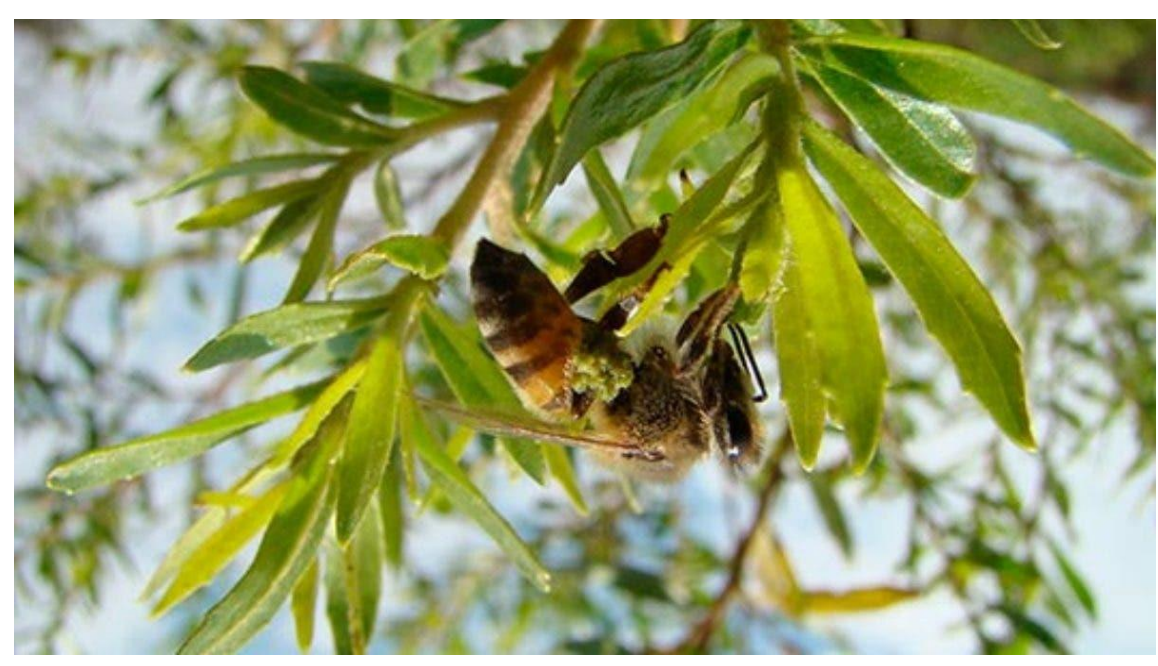

FONTE: https://www.greenmebrasil.com 
A própolis verde é uma mistura complexa, que possui material resinoso e balsâmico na qual as responsáveis para a sua produção são as abelhas, ou seja, as abelhas fazem a coleta desse produto, retirando diretamente de plantas, ramos, flores, brotos ou a extração de algumas árvores, e na colmeia as abelhas acrescentam secreções. (BURDOCK, 2008). É dentro da colmeia que ocorre a impermeabilização, isolamento térmico, vedação e tratamento antisséptico para a produção desse produto (LUSTOSA, 2008).

Como as abelhas (Figura 2), são responsáveis pela produção da própolis verde, elas são oriundas das vespas, na qual deixaram de se alimentar de pequenos insetos e aranhas para consumirem o pólen das flores. As abelhas tem um papel fundamental na manutenção da biodiversidade, pois ao retirarem os pólens das flores para a produção base da própolis, contribuem com a polinização. As abelhas como um todo são os principais agentes polinizadores de plantas, na qual retiram o néctar, o pólen e resinas para a produção essencial da própolis. A própolis tem como função principal na colmeia, proteger o habitat das abelhas contra insetos e microrganismos empregando-as em finas camadas nas paredes internas das colmeias, para vedar buracos e rachaduras, reparar e fortalecer os favos de mel e proteger a entrada da colmeia (SILVA e PAZ, 2012).

FIGURA 2: Representação da espécie de abelhas Apis melífera.

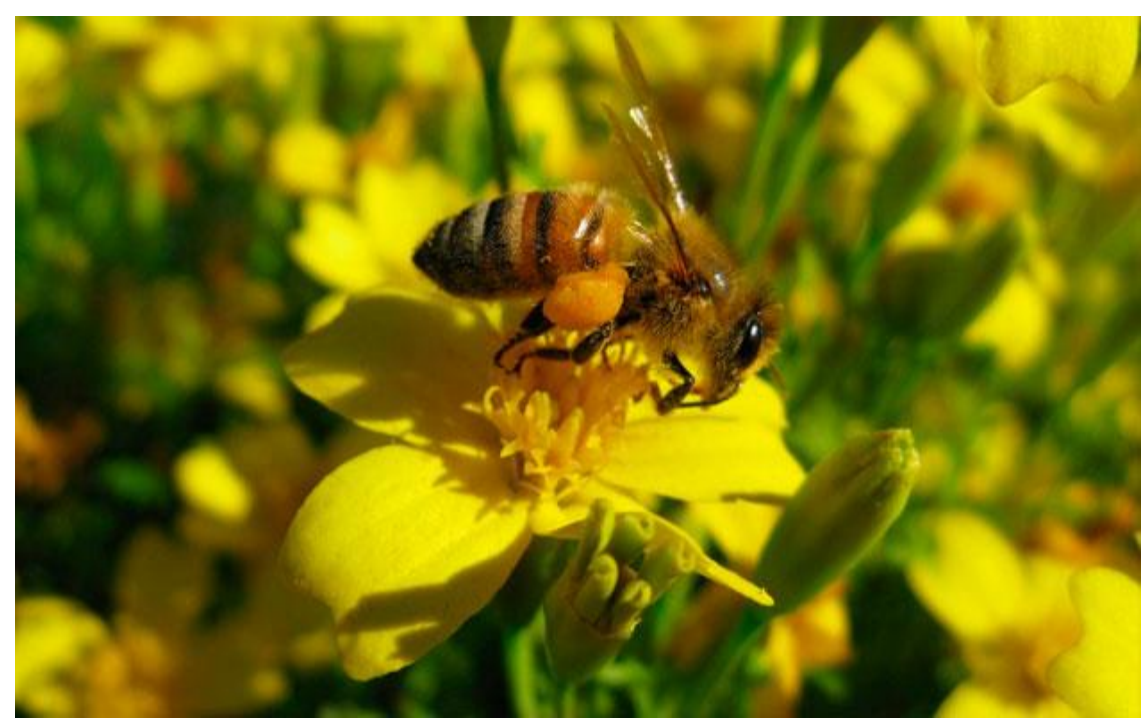

FONTE:Biologo.com.br 
São considerados como os principais grupos químicos encontrados na própolis verde, a flavonóides (Figura 3), como a galangina, quercetina, pinocembrina e kaempferol, além de terpenóides e fenilpropanóides como os ácidos cafeico (Figura 4) e clorogênico. (SANTOS, 2018). E os componentes ativos, mais importante da própolis são ácidos aromáticos, compostos fenólicos, em especial flavonóides (flavonas, flavonóis e flavononas) e ácidos fenólicos (KORU, 2007). As propriedades terapêuticas encontradas na própolis, os flavonóides e diversos compostos fenólicos são responsáveis pela produção e os efeitos qualitativos quanto ao seu uso (SANTOS,2018).

FIGURA3: Estrutura molecular dos flavonoides<smiles>O=c1cc(-c2ccc(O)cc2)oc2cc(O)cc(O)c12</smiles>

FONTE: engquimicasantossp.com.br

FIGURA 4: Estrutura molecular dos ácidos cafeico

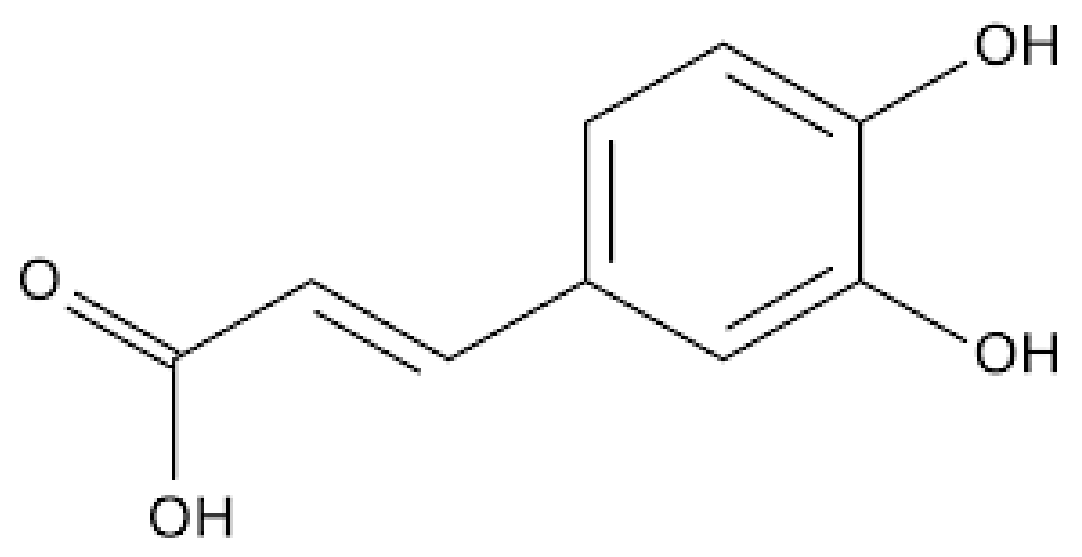

FONTE: engquimicasantossp.com.br 


\subsection{Características Terapêuticas da Própolis Verde}

\subsubsection{Propriedades Biológicas}

A própolis verde se tornou em algo de utilização popular na sociedade, pois tem a capacidade de produzir atividades farmacológicas de cunho terapêutico e sem restrição de uso, tais como antimicrobiana, antioxidante, antiinflamatória, imunomoduladora, hipotensiva, cicatrizante, anestésica, anticâncer, anti-HIV e anticarcinogênica. (RIBEIRO; COLOMBARI, 2006).

\subsubsection{Interligado as atividades anti-inflamatórias}

A própolis verde é um produto utilizado mundialmente, pois tem como indicação terapêutica quanto prevenção e redução de doenças inflamatórias, oriundas de cunho cardíacos, diabetes, renal e câncer (LEMOS et al,2013). Algumas complexidades também são sanadas com a inserção da própolis verde, como mau hálito (halitose), eczema, infecções na garganta, úlceras e infecções urinárias (RICHARDS et al,200o).

Estudos confirmam sobre as propriedades anti-inflamatória que a própolis verde desenvolve no organismo do paciente, por causa da presença dos flavonóides, na qual apresenta atividade inibitória contra a ciclooxigenase (COX) e lipooxigenase. $\mathrm{O}$ ácido fenil éster caféico (CAPE), possui atividade antiinflamatória por inibir a liberação de ácido aracdônico da membrana celular, suprimindo as atividades das enzimas COX-1 e COX-2 (RESENDE et al,2007).

Em relação as atividades anti-inflamatória, a própolis verde tem a capacidade de

inibir a síntese das prostaglandinas, ativar a glândula timo, auxiliando o sistema imune pela promoção da atividade fagocítica e estimulando a imunidade celular, desenvolvendo capacidade terapêutica contra qualquer tipo de inflamação no organismo do paciente, e prevenindo outros tipos de complexidade ao tratamento (RICHARDS et al,200o).

\subsubsection{Própolis verde e as atividades antimicrobiana}

Em relação as atividades antibacteriana e antifúngica, a própolis possui propriedades biológicas com grande eficácia para qualquer tipo de tratamento que 
dependa da sua eficácia como resultado qualitativo (DIEDRICH,2015). São atribuídas principalmente à flavonona pinocembrina, ao flavonol galagina e ao éster feniletil do ácido caféico, com um mecanismo de ação baseado provavelmente na inibição do RNA-polimerase bacteriano (FUJIMOTO et al,2016).

Quanto a potencialidade do uso do extrato de própolis em relação as atividades antimicrobiana, proporciona capacidade de constituir atividades biológicas qualitativa quanto aos efeitos relacionados a sua baixa toxicidade e a possibilidade de sua utilização como antimicrobiano alternativo à inibição de micro-organismos resistentes à antibióticos (CAMPOS,2019).

O uso de extratos de própolis verde é considerado como uma alternativa para a inibição de patógenos oportunistas emergentes como Enterococcus. Este tipo é considerado por ser responsável pela terceira maior causa de bacteremia e segunda maior causadora de infecções de cunho urinário em diversos âmbitos hospitalares nas

últimas décadas (GOMEZ et al., 20II; RICHARDS et al., 2000). Sendo considerado um dos principais fornecimentos que ocasionam a prevalência da mastite bovina (ELHADIDY; ELSAYYAD, 2013).

Estudos confirmam que o extrato da própolis verde desenvolve no organismo atividade antimicrobiana contra bactérias Gram-positivas, e atividade menos evidente contra Gram-negativos, pois essas bactérias possuem uma parede celular quimicamente mais complexa e um teor lipídico maior, o que pode explicar essa maior resistência quando executado de forma coerente e prescrita corretamente quanto ao seu uso (CAMPOS,2019).

\section{DISCUSSÃO}

A análise para o desenvolvimento deste estudo, são considerados unânimes ao afirmarem que a utilização da própolis verde na suplementação alimentar, desenvolve no indivíduo qualidade em sua saúde, principalmente relacionado a atividades antimicrobiana e anti-inflamatória (MENEZES, 2005).

De acordo com Lacerda et al (20II), considera em seus estudos que o uso da própolis brasileira como tratamento terapêutico é considerada melhor atividade antimicrobiana em todos os aspectos. Estudos identificaram diferenças qualitativas e 
quantitativas na sua composição química, capazes de produzir resultados eficientes ao seu uso com moderação (PEREIRA,20II).

Estudos desenvolvidos por Oliveira (2019), apresentaram a alta atividade antibacteriana da própolis frente a bactéria Staphylococcus aureus. O trabalho apresentado por De-Melo et al (2014), por sua vez, mostrou a eficácia do extrato da própolis verde não apenas ao combate as bactérias, mas a capacidade de produzir atividades anti-inflamatória. Entre as espécies de bactérias sensíveis, estão as dos gêneros Staphylococcus, Nocardia, Streptococcus, Rhodococcus (gram-positivas) e Pseudomonnas, Proteus, Escherichia (gram-negativas) (PEREIRA,20II).

\section{CONCLUSÃO}

A própolis verde por ser uma substância natural e apresentar uma potencialidade em múltiplas atividades biológicas benéficas no tratamento e prevenção de doenças decorrente de seu efeito antioxidante, torna usa utilização de suma importância no tratamento terapêutico devido sua atividade antimicrobiana, anti-inflamatória, cicatrizante, anestésica e anticarciogênica, quanto pela possibilidade de aplicação na indústria farmacêutica e alimentícia.

Estudos apontam que com o uso de doses recomendadas de segurança da própolis verde, promove nos indivíduos percepção de melhoras que são percebidas durante o tratamento proposto e estabelecido em um determinado prazo de tempo orientado pelo profissional de Nutrição. A própolis verde tem um papel relevante como tratamento terapêutico, contribuindo de forma satisfatória aos tratamentos de diversas complexidades, principalmente problemas vasculares, diabetes, hipertensão e trazem contribuições muito valiosas para que o nutricionista consiga fazer uso deste nutriente tão significativo e valioso e de grande importância para a manutenção e tratamento do estado nutricional dos indivíduos.

\section{REFERÊNCIAS BIBLIOGRÁFICAS}

ADELMAN, José. Própolis: variabilidade composicional, correlação com a flora e bioatividade antimicrobiana / antioxidante, 2005. 176f. Dissertação (Mestrado em Ciência Farmacêutica) -Universidade Federal do Paraná, Curitiba, 2005. 
BANKOVA VS, CASTRO SLD, MARCUCCI MC. Própolis: avanços recentes na química e origem vegetal Apidologie. Faculdade de Farmácia, Universidade Bandeirante de São Paulo. São Paulo.200o;3I(I):3-I5.

BURDOCK, G. A. Review of the biological properties and toxicity of bee propolis (propolis). Food and Chemical Toxicology, v. 36, n.4 p. 347-363, apr. 1998

CAMPOS, T. M. C. Avaliação de atividades antimicrobianas e antiparasitárias dos extratos alcoólico e aquoso da própolis de Scaptotrigona affinis postiça. Tese de Mestrado. São Paulo: Instituto Butantan; p. III, 2019.

DE-MELO, Adriane Alexandre Machado et al. Capacidade antioxidante da própolis. Pesquisa Agropecuária Tropical [online]. 2014, v. 44, n. 3 [Acessado 4 Outubro 202I], pp. 34I-348. Disponível em: <https://doi.org

DIEDRICH, C. Atividade Antimicrobiana De Extratos De Própolis Produzidas Por Abelhas Apis Mellifera Selecionadas. Universidade Tecnológica Federal do Paraná, 2015 .

ELHADIDY, M.; ELSAYYAD, A. Uncommitted role of enterococcal surface protein, Esp, and origin of isolates on biofilm production by Enterococcus faecalis isolated from bovine mastitis. Journal of Microbiology, Immunology and Infection, v. 46, p. $80-84,2013$.

FUJIMOTO, Graciela et al. Própolis verde: caracterização, potencial de atividade antimicrobiana e efeitos sobre biofilmes de Enterococcus spp. 2016. 
GOMEZ et al. Intra and Interspecies Genomic Transfer of the Enterococcus faecalis Pathogenicity Island. PLoS ONE. v.6, er6720, 2011

HOJO, P. A. Extração de compostos bioativos de própolis verde por alta pressão isostática. Dissertação de Mestrado apresentada ao Programa de Pós-Graduação em Tecnologia de Alimentos da Faculdade de Engenharia de Alimentos da Universidade Estadual de Campinas como parte dos requisitos exigidos para obtenção do título de Mestra em Tecnologia de Alimentos, 2017.

KORU O. et al. In vitro antimicrobial activity of propolis samples from different geographical origins against certain oral pathogens. Anaerobe., v.13, p.I40-I45, 2007.

LACERDA, R. C. C. TIVERON, A. P. AlenCAR, S. M. Própolis e Segurança Alimentar. Pós-graduação em Ciência e Tecnologia de Alimentos, Depto. de Agroindústria, Alimentos e Nutrição - Escola Superior de Agricultura Luiz de Queiroz (ESALQ), Universidade de São Paulo (USP), Piracicaba, SP. 201 I

LEMOS Júnior, H. P.; LEMOS, A. L. A. Própolis diagnóstico tratamento ; I8(I)jan.mar. Artigo em Português | LILACS | ID: lil-670589, 2013.

LUSTOSA, S. R. et al. Própolis: atualizações sobre a química e a farmacologia. Revista Brasileira de Farmacognosia [online], v. I8, n. 3, 2008.

MENEZES, H. Própolis: uma revisão dos recentes estudos de suas propriedades farmacológicas. Dissertação (Mestrado em Ciências)-Universidade Estadual 
Paulista, Instituto de Biociências, Departamento de Bioquímica e Microbiologia, Arq. Inst. Biol., São Paulo, 2005.

OLIVEIRA, Laís Aryel Andrade De. Potencial antimicrobiano dos extratos de própolis (verde, vermelha e marrom). Universidade Federal Rural do Semi-árido, Curso de Zootecnia, Mossoró, Rio Grande do Norte, RN.2ol9.

PENSIN, N. R.; PENSIN, C.; MIURA, C. S. N.; BOLETA, D. C. F. Efeito de pomada de própolis em orabase para tratamento de ulcerações aftosas recorrentes um estudo piloto. Arq. ciências saúde UNIPAR ; 13(3): 199-204, set.-dez. 2009.

RESENDE et al. Brazilian green propolis on Heliobacter pylori infection. A pilot clinical study. Helicobacter, no 12, p.572-574, 2007

RIBEIRO, A. F. J. M. M.; COLOMBARI, L. V. Atividade antimicrobiana de própolis de Apis mellifera obtidas em três regiões do Brasil. Ciênc. Rural, v.36, n.I, p.294-297, 2006.

RICHARDS, M.J. et al. Nosocomial infections in combined medical-surgical intensive care units in the United States. Infection Control Hospital Epidemiology, v. 2I, p. 510-515, 2000.

SANTOS, P. B. R. E. Atividade antimicrobiana de extratos de própolis sobre cepas clínicas de Pseudomonas aeruginosa e Klebsiella pneumoniae multirresistentes. São José dos Campos; s.n;6I p. il., tab., graf.. Tese em Português| BBO - Odontologia | ID: biblio-968464, 2018. 
SILVA, W. P.; PAZ, J. R. L. Abelhas sem ferrão: muito mais do que uma importância econômica. Natureza Online, Santa Teresa, v. Io, n. 3, p. I46-I52, 2012.

SILVA, C. C. F. Análise química e atividades antioxidante e citotóxica de amostras de própolis de alecrim 2008. Iıo f. Dissertação (Mestrado em Ciências) - Instituto de Biociências, Universidade de São Paulo, São Paulo, 2008.

PEREIRA, I. N. Própolis: matéria-prima de potencial aplicação farmacêutica. 201 I. 55p. (Trabalho de conclusão de estágio). Universidade Federal do Rio Grande do Sul. Porto Alegre. 20II.

PINTO, L. M. A. DO PRADO, N. R. T. DE CARVAlHO, L. B. Propriedades, usos e aplicações da própolis. Revista Eletrônica de Farmácia Vol. VIII (3), 76 - ıo, 2011

XU X, YANG B, WANG D, ZHU Y, MIAO X, YANG W. A composição química da própolis verde brasileira e seus efeitos protetores nas células endoteliais da aorta de camundongo contra lesão inflamatória. Moléculas .2020; 25 (20): 4612. Disponível em: https://doi.org. Acesso em: 04 de out.2021. 